\title{
As narrativas históricas gráficas como expressão da aprendizagem histórica de jovens estudantes do ensino médio: perspectivas da educação histórica
}

\author{
Graphic historical narratives as expression of historical learning \\ of young high school students: perspectives in History education
}

Marcelo Fronza ${ }^{*}$

\section{RESUMo}

Este artigo investiga como os jovens estudantes de ensino médio brasileiros expressam sua consciência histórica com base em suas narrativas históricas gráficas. Tem como objetivo oferecer aproximações teóricas sobre como é possível abordar, dentro da Educação Histórica, as histórias em quadrinhos construídas pelos estudantes considerando as discussões sobre narrativa histórica como formas de aprendizagem histórica ligadas aos tipos de disposição da consciência histórica desses sujeitos. Buscou-se compreender se os conceitos de intersubjetividade e verdade, ligados à identidade histórica dos jovens, interferem na orientação de sentido no tempo quando eles produzem suas próprias narrativas históricas gráficas.

Palavras-chave: aprendizagem histórica; consciência histórica; verdade histórica e intersubjetividade; histórias em quadrinhos.

\section{Abstract}

This paper investigates how young Brazilian high school young students express their historical consciousness from their graphic historical narratives. This paper aims to provide theoretical approaches on how is possible address, within the history education, the historical comic books built by students considering the discussions about historical narrative as ways to grasp the types of disposal of the historical consciousness of these individuals. The objective was to understand the concepts of intersubjectivity and truth, related to the identity, interfere within the sense orientation in time of young people when they produce their own graphic historical narratives.

Keywords: historical learning; historical consciousness; historical truth and intersubjectivity; historical comic books.

\footnotetext{
* Doutor em Educação. Universidade Federal de Mato Grosso (UFMT). Pesquisador do grupo de pesquisa Educação Histórica: consciência histórica e narrativas visuais (UFMT) e do Laboratório de Pesquisa em Educação Histórica (LAPEDUH), da Universidade Federal do Paraná (UFPR). Cuiabá, MT, Brasil. fronzam34@yahoo.com.br
} 
Este artigo é fruto dos estudos desenvolvidos no grupo de professores historiadores ligado ao Laboratório de Pesquisa em Educação Histórica (LAPEDUH-UFPR) e ao Grupo de pesquisa Educação Histórica - Didática da História, consciência histórica e narrativas visuais/UFMT, os quais investigam a cognição histórica situada (Schmidt, 2009, p.22) que tem seus princípios e finalidades ancorados na epistemologia da História e servem de embasamento à área de pesquisa da Educação Histórica, um campo de investigação que estuda as ideias históricas dos sujeitos em contextos de escolarização, de modo que é estruturada por pesquisas empíricas que dialogam com a teoria da consciência histórica (Rüsen, 2001; 2012). Meu objetivo é compreender se os conceitos de intersubjetividade e verdade, ligados à identidade, interferem na orientação de sentido no tempo, dos jovens, quando eles produzem as suas próprias narrativas históricas gráficas.

Entendo que as discussões sobre narrativa histórica podem fornecer algumas formas de compreender os tipos de disposição da consciência histórica: afirmação, regularidade, negação e transformação, as quais são expressas, respectivamente, pelas narrativas tradicionais, exemplares, críticas e genéticas. Além disso, é pela narrativa histórica presente tanto nas histórias em quadrinhos, quanto como fator estruturador das ideias históricas dos jovens estudantes, que pude investigar, com as categorias sobre intersubjetividade e verdade, os conceitos históricos substantivos e os de segunda ordem ${ }^{1}$ expressos por aqueles sujeitos.

Este trabalho é estruturado em duas partes. A primeira discute a ideia de que a narrativa é um princípio epistemológico da História. Para isso, lancei mão das investigações de James V. Wertsch (Wertsch, 2006; Rozin, 2004) e do conceito de protonarrativa de Jörn Rüsen (2001). Também mobilizei os conceitos de imagem canônica e imagem alternativa do Elias Tomé Saliba (1999). A segunda parte diz respeito à análise das narrativas históricas gráficas dos jovens investigadas com base no modo como constroem sua intersubjetividade por meio da afirmação, imitação, negação ou transformação em relação à tradição sobre a experiência histórica da Independência do Brasil. 


\section{A NARRATIVA COMO PRINCÍPIO EPISTEMOLÓGICO DA HistóRIA}

Sabe-se que a narrativa gráfica é uma das conceitualizações estruturantes das histórias em quadrinhos, e isso possibilita que os jovens desenvolvam a capacidade de reconstruir suas ideias na forma de uma narrativa.

Entendo que as considerações teóricas advindas do investigador James V. Wertsch (Wertsch, 2006; Wertsch; Rozin, 2004) podem ser úteis na compreensão das narrativas históricas desenhadas pelos jovens. Utilizando o conceito de "dialogicidade oculta" criado por Mikhail Bakhtin (1997), James Wertsch e Mark Rozin investigam as narrativas produzidas entre 1992 e 1993 por cidadãos russos da antiga União Soviética; sobre como representam o passado (especificamente a revolução de 1917). Para esses autores tais narrativas são "objetos de resistência" ou "contratextos" em relação às narrativas históricas oficiais daquela nação.

Nessa mesma direção, o historiador alemão Jörn Rüsen (2001) compreende as protonarrativas como uma estrutura narrativa em que "o quotidiano está cheio de elementos fragmentados das histórias, de alusões a histórias, de parcelas de memória, de 'narrativas abreviadas'”. As protonarrativas são unidades básicas de sentido que estão articuladas a uma tradição, em que as experiências do passado, as expectativas de futuro e suas intencionalidades e as orientações do sentido de agir no tempo ainda são distinguidas umas das outras e não têm a capacidade de se criticarem.

Com isso, busca-se investigar as narrativas históricas gráficas produzidas pelos jovens, os quais puderam se apropriar da dimensão estética das histórias em quadrinhos que podem revelar, seja um conjunto de imagens canônicas (Saliba, 1999), seja uma criação ativa por meio dessas imagens (Lukács, 2003; 2010). Para entender esse processo criativo e sua relação com a intersubjetividade e verdade, as teorias ligadas à dimensão estética da cultura histórica são de grande valia.

Para Elias Tomé Saliba (1999, p.440), assim como para Rüsen (2001), Snyders (1988), Bakhtin (2000) e McCloud (2005), o professor de história, com seus alunos, poderia fazer um ordenamento do tempo que supere o presentismo inerente às imagens canônicas e dominantes na condição juvenil. Saliba compreende o ordenamento no tempo como uma "operação crítica" de comparação, aproximação e distanciamento temporal das imagens e seus significados. 
Em proximidade com as ideias de Lukács (2010), afirma que criticar as imagens é tentar "quebrar com o efeito de real que elas provocam". Para isso, é necessário sintetizar a análise das imagens contra a superabundância na mídia e na sociedade.

O uso de imagens alternativas, que causem o sentimento estético do humor, pode ser vital porque possibilitam a consciência do distanciamento entre o passado e o presente, abrindo espaço, assim, para um primeiro passo de um processo de ordenamento do tempo. Rüsen (2001) e Snyders (1988) já defendiam a importância do estabelecimento de um fio condutor na construção das narrativas; Bakhtin (2000) atentou para os valores que as imagens podem revelar no diálogo com outras imagens pertencentes a outras épocas passadas da grande temporalidade da humanidade; e McCloud (2006) indicou que, ao contrário das imagens representadas em um eterno presente, as histórias em quadrinhos, em sua narrativa, apresentam um mapa temporal onde a experiência do passado, do presente e do futuro estão unidas graficamente.

As imagens canônicas dificultam diálogos, a não ser os estereotipados. Já as imagens alternativas se sustentam nesses diálogos, mesmo quando implícitos. Para Bakhtin (1997, p.87-88) as ideias, na dimensão da vida prática, não estão restritas à consciência individual, mas sim à comunicação dialogada entre as consciências. "A ideia é um acontecimento vivo que irrompe no ponto de contato dialogado entre duas ou várias consciências", demarcando assim seu posicionamento perante o mundo da vida prática. Só é possível se relacionar em relação à posição do outro, como uma resposta ao outro. Dessa forma, as ideias assumem a complexidade contraditória de uma "ideia-força, que nasce, vive e atua no grande diálogo da época e guarda semelhança com as ideias cognatas de outras épocas". A relação temporal entre as ideias as transforma em imagem: a imagem de uma ideia. Como ela se constituiu na relação dialógica com outras ideias do passado e com as que ainda estão nascendo para se expandir no futuro, a ideia tornada imagem é sempre "interindividual e intersubjetiva".

Busquei compreender se a natureza narrativa das histórias em quadrinhos modifica a natureza do pensamento histórico. Isso porque tenho como hipótese que o uso de um artefato da cultura histórica, próprio da cultura juvenil, como as histórias em quadrinhos, pode dinamizar as narrativas históricas que permitem a construção de uma cognição histórica situada nos jovens das 
escolas de ensino médio, produzindo, assim, uma aprendizagem histórica significativa.

Com base na ideia de que a natureza narrativa das histórias em quadrinhos transforma as operações mentais da consciência histórica, constatei: as histórias em quadrinhos se assemelham às ideias propostas por James Wertsch (2006) e Rüsen (2001, p. 75) referentes às estruturas narrativas esquemáticas e as narrativas históricas. A partir daí, entendo que as histórias em quadrinhos possibilitam o aparecimento de construtos de narrativas históricas mais sofisticadas, por meio da mobilização, pelos sujeitos, das ideias relativas à verdade histórica e à intersubjetividade.

\section{A INTERSUbJETIVIDADE E A EXPRESSÃO DA CONSCIÊNCIA HISTÓRICA DOS JOVENS}

O público alvo dessa pesquisa são 125 estudantes, com idades de 14 a 28 anos, do segundo ano do ensino médio de quatro escolas públicas brasileiras: em São João dos Patos, Maranhão (43 estudantes); Três Lagoas, Mato Grosso do Sul (26 estudantes); Vitória da Conquista, Bahia (33 estudantes), e Curitiba, Paraná (23 estudantes). Os estudantes desses colégios foram investigados em 9, 18 e 30 de maio e 6 de outubro de 2011, respectivamente. Para isso, produzi um instrumento de investigação baseado nos critérios metodológicos da pesquisa qualitativa, a partir do trabalho de Michelle Lessard-Hébert (LessardHébert; Goyette; Boutin, 2005). As narrativas gráficas dos jovens foram analisadas a partir da décima pergunta, advinda do instrumento de investigação de minha tese (Fronza, 2012, p.450-454):

Imagine que você está numa feira de quadrinhos históricos e os jovens que estão lá pedem que narre a sua versão sobre a Independência do Brasil, na forma de uma história em quadrinhos. Por favor, procure desenhar essa versão.

As narrativas gráficas dos jovens foram organizadas pelos tipos de relação entre a intersubjetividade e a consciência histórica que elas expressam. No entanto, é preciso ter claro que nas respostas desenvolvidas às questões do instrumento de investigação, cuja análise encontra-se nos capítulos 3, 4 e 5 de minha tese de doutorado (Fronza, 2012), esses estudantes não expressaram, 
necessariamente, o mesmo tipo de consciência histórica que os manifestados em suas narrativas em imagens. Foram selecionados aqui quatro jovens que apresentaram em suas histórias em quadrinhos quatro disposições distintas em relação à sua consciência histórica.

Filha e irmã de operadoras de caixa e de um pai autônomo, a jovem Mafalda $^{2}$ é de Curitiba e sempre estudou em escolas públicas. Com relação à sua concepção de História, ela entende que esse conhecimento ajuda na formação da sociedade contemporânea, expressando assim a ideia de que o passado orienta o sentido da vida prática no presente. Para ela é possível aprender história com a narrativa dos quadrinhos, porque as crianças e jovens preferem-na aos livros formais. Portanto, ela faz uma diferenciação entre os quadrinhos e os livros didáticos. Com relação à verdade histórica das narrativas gráficas, Mafalda se mostrou cética ao afirmar que ninguém sabe sobre a verdadeira história da humanidade. Por isso, cada um cria uma hipótese ou aceita o que aprendeu da tradição.

Em coerência com sua resposta sobre a possibilidade de os quadrinhos contarem a verdade sobre o passado, Mafalda defendeu uma concepção perspectivada de qual seria a melhor história sobre a Independência, porque, mesmo considerando que a melhor é definitivamente verdadeira, segundo a jovem, só é possível atingi-la a partir da criação de novas hipóteses, para que a versão possa ser completada. Mafalda também argumentou que a versão mais confiável estabelece melhor comunicação com o leitor, por meio da explicitação dos detalhes e pela comparação entre perspectivas.

À luz desta explanação, posso afirmar que essa jovem oscila entre uma disposição da afirmação da tradição até uma negação da mesma, por meio do ceticismo e da multiperspectividade. Portanto, ela dialoga com a consciência histórica tradicional e a crítica. Assim, Mafalda compôs sua história em quadrinhos: 


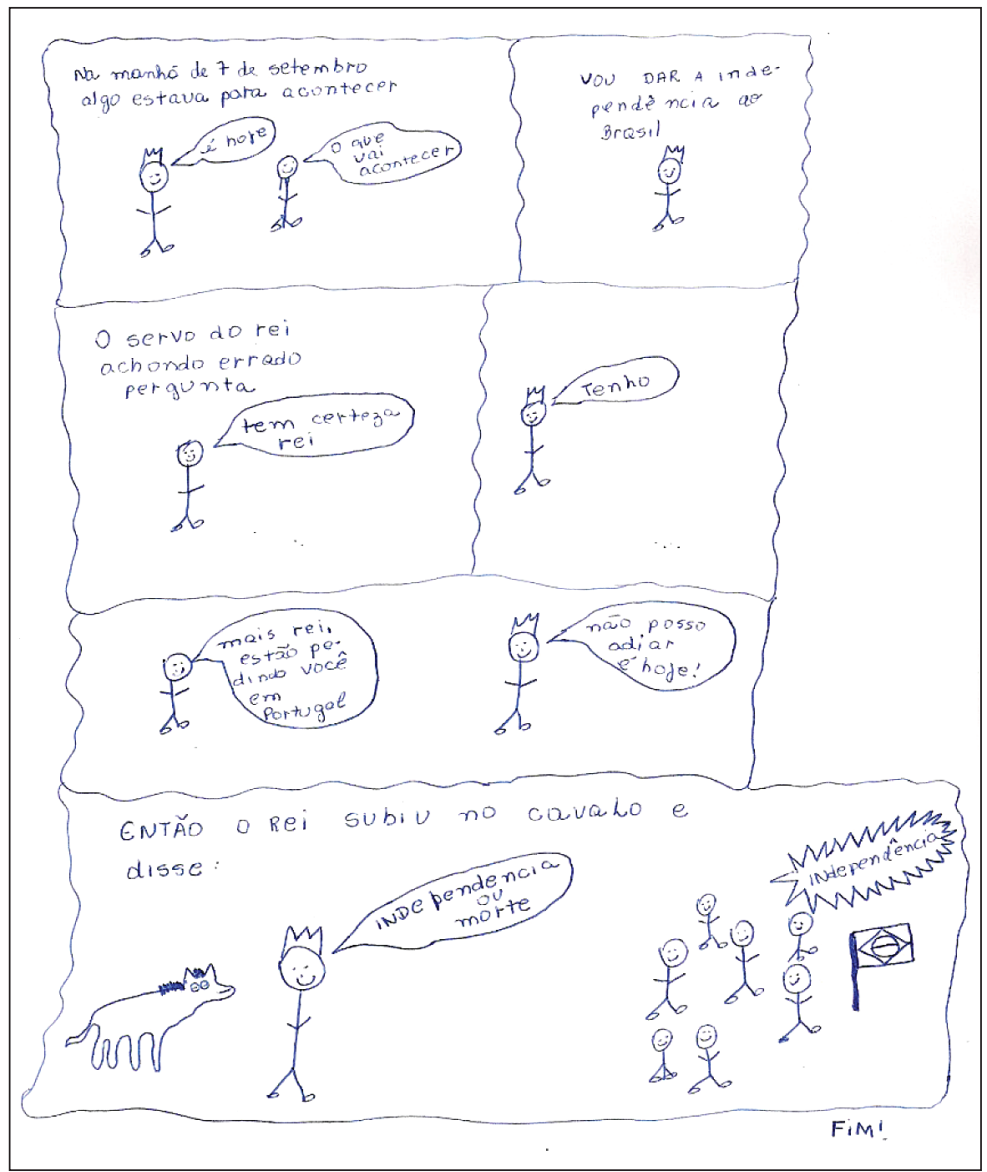

Figura 1 - Mafalda, 16 anos, Curitiba, PR

Mafalda expressou em sua história em quadrinhos uma consciência histórica tradicional, na medida em que essa estudante paranaense claramente representa uma afirmação da tradição nas imagens representadas. O primeiro vestígio dessa concepção é o ícone de D. Pedro já coroado antes da declaração da Independência, revelando o poder imagético do arquétipo do rei, vindo de uma centenária tradição popular no Brasil. Outros indícios de uma tradição nacional são a explicitação da data de 7 de setembro e da bandeira nacional em locais chaves da narrativa - no primeiro e no último quadrinho. A bandeira, aliás, representa a vontade do povo brasileiro. 
A afirmação da identidade nacional é tão forte na subjetivação das imagens canônicas (Saliba, 1999) representadas por Mafalda, que a situação do passado mais importante descrita por ela, nas questões investigativas, está ausente nos seus quadrinhos - a entrega da carta a D. Pedro informando que ele deveria voltar a Portugal. Com isso, entendo que, sob esse aspecto, a intersubjetividade dessa jovem está intimamente ligada à tradição.

Como explicar a oscilação nas respostas de Mafalda entre uma atitude de afirmação tradicional e atitudes críticas e multiperspectivadas, que não se revelaram nas imagens em quadrinhos?

Entendo que a resposta está ligada ao poder hegemônico das imagens canônicas (Saliba, 1999); essas correspondem a uma visão alienante em relação aos ícones. A onipresença da imagem da pintura de Pedro Américo em todas as fontes com as quais os jovens têm contato quando estudam, leem ou veem sobre a Independência do Brasil, tem um poder de banalização que invade a estruturas da sua consciência histórica.

Este é o perigo do uso público indiscriminado e irracional das imagens: os jovens tendem a se tornar reféns das concepções tradicionais e exemplares presentes na cultura histórica. É preciso ter claro que selecionei uma jovem que expressou essa atitude conservadora da História, mas ela está presente na maioria das produções em quadrinhos realizadas tanto no estudo piloto como no final (Fronza, 2012).

No entanto, muitos estudantes tentaram resistir ao poder canônico dessas imagens e procuraram comunicar o seu posicionamento, seja de exemplaridade, de negação ou de transformação, por meio de imagens alternativas (Saliba, 1999).

Valéria é filha de uma cozinheira e de um secretário; sempre estudou na escola pública e sua família veio da Bahia. Ela considera o conhecimento sobre o passado como uma forma de aprendizagem para a vida prática. Entende que a veracidade das histórias em quadrinhos está relacionada às pesquisas históricas. No entanto, para ela os livros são melhores que os quadrinhos para aprender História, pois estes últimos limitam a capacidade imaginativa existente nos primeiros. Valéria entende que os quadrinhos podem contar a verdade sobre a humanidade, mas de uma maneira mais lúdica. Considerou que a autoridade de um autor importante e de uma testemunha de época dá confiabilidade a uma história. 
Conforme os dados empíricos apresentados é perceptível nessa jovem uma consciência histórica tradicional, pois ela se baseia numa concepção dogmática do passado, pautada em acertos e erros. Isso, apesar do fato de apreciar muito o conhecimento do passado, mesmo em espaços de experiências distintos dos da cultura escolar. Assim ela representa seus quadrinhos:

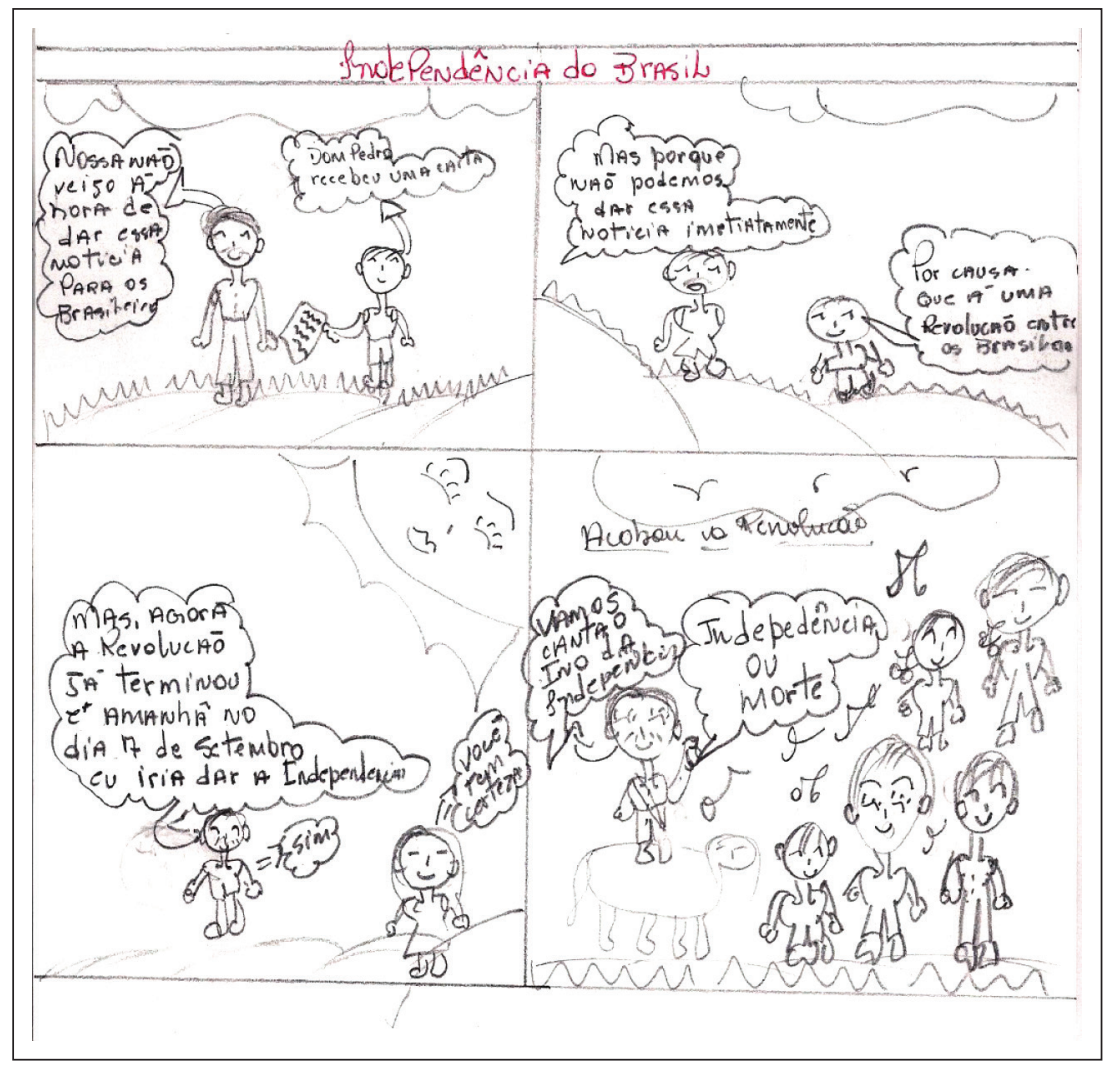

Figura 2 - Valéria, 15 anos, Três Lagoas, MS

Valéria apresenta uma história em quadrinhos que expressa uma atitude afirmativa em relação à tradição da cultura histórica sobre a Independência, típica de uma consciência histórica exemplar. A exemplaridade dessa representação se dá porque essa jovem se representa na história, que pode estar se passando no presente, como se fosse uma peça de teatro. $\mathrm{O}$ mais interessante nessa narrativa gráfica, porém, é o aprofundamento cognitivo do conteúdo 
histórico, que não aparece na produção dos outros jovens investigados. Ela cita a revolução liberal que aconteceu em Portugal (aqui a jovem apresenta uma diferença em relação à historiografia ao apontar que a revolução é dos brasileiros) e que fez os portugueses desejarem retirar a autonomia brasileira em relação à metrópole. Ela relaciona o fim dessa revolução com o início da Independência do Brasil.

Outra característica de uma imagem alternativa em relação às imagens canônicas sobre a Independência é que os personagens cartum (McCloud, 2005), representados por Valéria, estão provavelmente atuando como se fosse uma peça de teatro, pois mesmo D. Pedro aparenta ser um personagem em atuação. Para reforçar o caráter alternativo dessas imagens, ela desenha uma menina que pode ser uma representação de si mesma. Outra estratégia estética muito mobilizada por essa jovem é o modo como o diálogo foi construído, pois, de fato, os personagens se comunicam entre si, como se o interlocutor não estivesse presente na leitura. A disposição estética parecida com um teatro ajuda a reforçar esse distanciamento. O caráter festivo dessa história em quadrinhos diz respeito a uma aceitação intersubjetiva, por essa jovem, da identidade nacional, expressa pelo canto do Hino da Independência.

O curioso é o uso sofisticado de elementos estéticos expressos no uso dos personagens cartum, representados como atores, nos diálogos que fornecem o timing - o ritmo -, à narrativa e à festa, representada pelos pentagramas musicais e pela alegria dos personagens, incluindo a representação de si mesma (Eisner, 1999; McCloud, 2005). Esse uso da dimensão estética da cultura histórica está voltado para uma subjetivação que afirma as narrativas vindas da tradição histórica, revelando a coerência dessa jovem e o domínio sobre esse conhecimento.

O saldo da análise dessa jovem estudante é que suas respostas às demais questões do estudo final revelaram uma consciência histórica tradicional que, ao ser transposta para as histórias em quadrinhos, foi mobilizada por meio da atitude de imitação exemplar da tradição pelo uso de estratégias estéticas ligadas aos quadrinhos, tais como os personagens cartum que representam os jovens, os diálogos e os cenários que buscam expressar o espírito lúdico nesses artefatos da cultura histórica.

Creio que a mesma resposta dada na categoria anterior pode ser repetida aqui, porque os poderes das imagens canônicas também têm o efeito de tornar 
o tradicional exemplar. Conforme Elias Tomé Saliba (1999), as imagens têm como características temporais uma referência imediata ao presente. Esse poder canônico das imagens propiciou a essa estudante a composição de imagens alternativas referentes à sua cultura juvenil: a festa e o brincar.

Micael é filho de uma operadora de máquinas de uma indústria de Três Lagoas, Mato Grosso do Sul. Sua família veio de Cuiabá, no Mato Grosso, e ele sempre estudou na escola pública. Compreende a História a partir da ideia da busca do passado por ele mesmo, seja por meio da arte, seja pelas palavras. Conhece muitos quadrinhos que narram a história do Brasil e da humanidade, dentre os quais destacou o Zé Carioca e vários personagens título da Turma da Mônica. Aprendeu em algumas dessas narrativas gráficas que Pedro Álvares Cabral "descobriu uma colônia" denominada Brasil que depois teve como capital a cidade de Salvador. Para ele, o personagem Zé Carioca representa a história do jeito brasileiro de viver, enquanto os personagens da Turma da Mônica dizem respeito ao modo de vida da humanidade como um todo. Ele quer dizer que ideias como a preguiça e a malandragem, ligadas ao personagem de Walt Disney, são uma especificidade brasileira; por outro lado, a criação de Maurício de Souza representa valores que podem ser compartilhados por toda a humanidade, dentre os quais a amizade.

Para esse jovem, as histórias em quadrinhos são importantes para a aprendizagem histórica, mas não devem estar sozinhas, pois existem bons programas culturais na TV pública brasileira que devem ser incorporados no ensino de História. Afirma que os quadrinhos podem narrar a verdade sobre o passado, se o autor fizer uso de acontecimentos plausíveis. A melhor história sobre a Independência, para ele, é a provavelmente verdadeira porque ou é plausível ou não é, e tem que ter um sentido de orientação no tempo. Essa probabilidade abre espaço para um ir além da simples interpretação histórica.

De modo geral esse jovem apresenta uma consciência histórica tradicional em suas respostas. Mas é preciso ter em conta que Micael considera o método histórico como um processo de validação das narrativas e que estas devem possibilitar a superação da mera narração do passado, pois devem fornecer um sentido de orientação no tempo ao jovem. Assim ele representou esse ir além da história: 


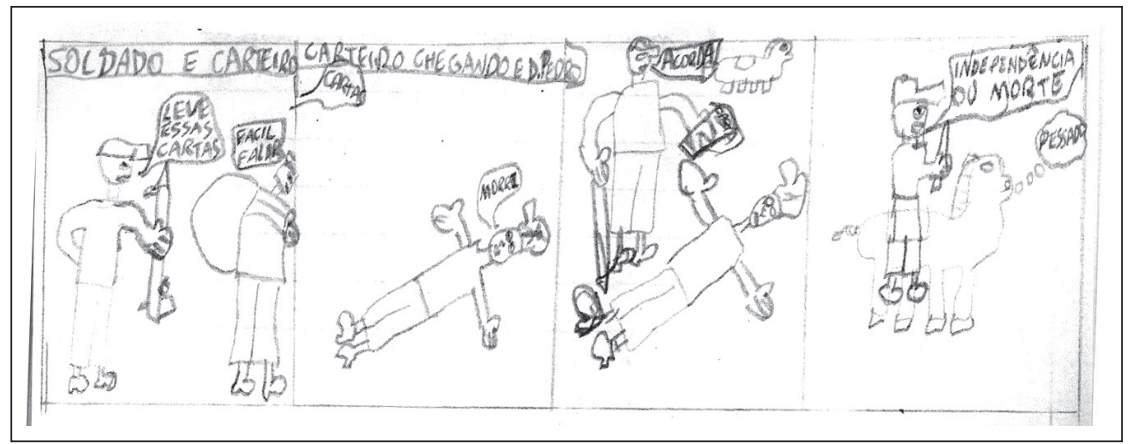

Figura 3 - Micael, 15 anos, Três Lagoas, MS

A história em quadrinhos desenhada por Micael é distinta da maioria das criações dos outros jovens, porque não foca totalmente em D. Pedro. O personagem principal dessa narrativa gráfica é o mensageiro. Este personagem é o responsável por acordar D. Pedro do seu sono e entregar a carta que propiciou a Independência do Brasil. Claramente a dimensão estética da cultura histórica instrumentaliza as estratégias cognitivas e políticas, porque a prioridade dessa narrativa é se comunicar de modo humorístico com o leitor. Os vestígios dessa estratégia estética estão nos balões de diálogo, bem compostos em seu aspecto retórico, pois, com uma linguagem popular, o carteiro expressa a dificuldade de sua missão, uma vez que D. Pedro é mal educado, arrogante e gordo conforme os balões desses personagens e do cavalo. Uma consciência histórica crítica se expressa nesses quadrinhos por conta da desestruturação estética da imagem canônica do grito da Independência e da autoridade de D. Pedro. As imagens do carteiro representam claramente uma imagem alternativa (Saliba, 1999) e contranarrativa (Wertsch; Rozin, 2004; Wertsch, 2006) em relação às narrativas tradicionais.

Filho de uma professora, Caio Márcio sempre estudou em escolas públicas e mora em Vitória da Conquista, Bahia. Entre outras atividades de lazer, ele aprecia ler histórias em quadrinhos, principalmente mangás, os quadrinhos japoneses que são um grande fenômeno da cultura juvenil contemporânea. Compreende a História como uma busca do passado por ele mesmo e considera que as histórias em quadrinhos desenvolvem o interesse das crianças pelo aprendizado histórico. Apresenta uma relação cética com esses artefatos da 
cultura histórica, porque acha que o governo não deve se preocupar com os quadrinhos. $^{3}$

Para esse jovem, D. Pedro é o personagem que realmente existiu e foi o único responsável pela Independência. Caio Márcio diz que a melhor história é definitivamente verdadeira porque está voltada para a aprendizagem e, por isso, não pode conter mentiras. Uma história em quadrinhos confiável deve ter um participante da situação do passado narrado, porque isso dá mais vida à História.

As argumentações desse jovem estão vinculadas às atitudes de afirmação ligadas a uma consciência histórica tradicional, na medida em que só uma versão pode ser plausível e que a verdade é sempre definitiva. Assim ele expressou em quadrinhos as suas ideias:

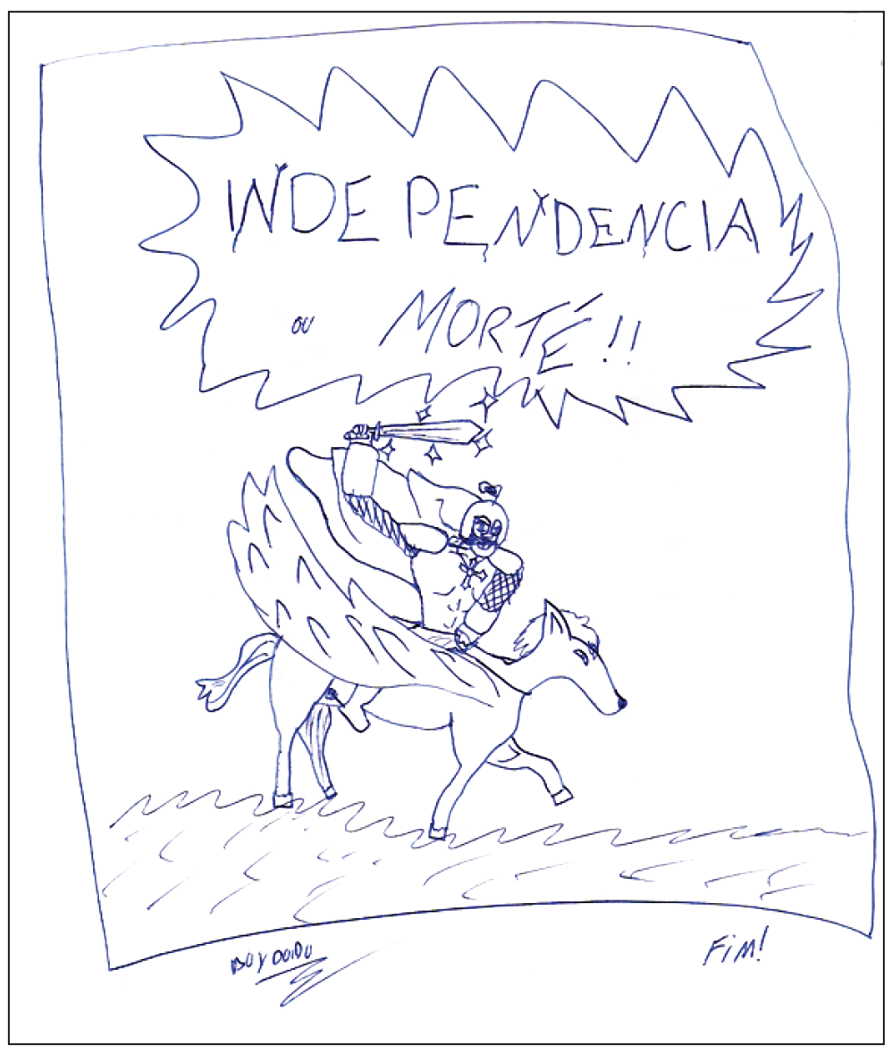

Figura 4 - Caio Márcio, 16 anos, Vitória da Conquista, BA (p.1) 


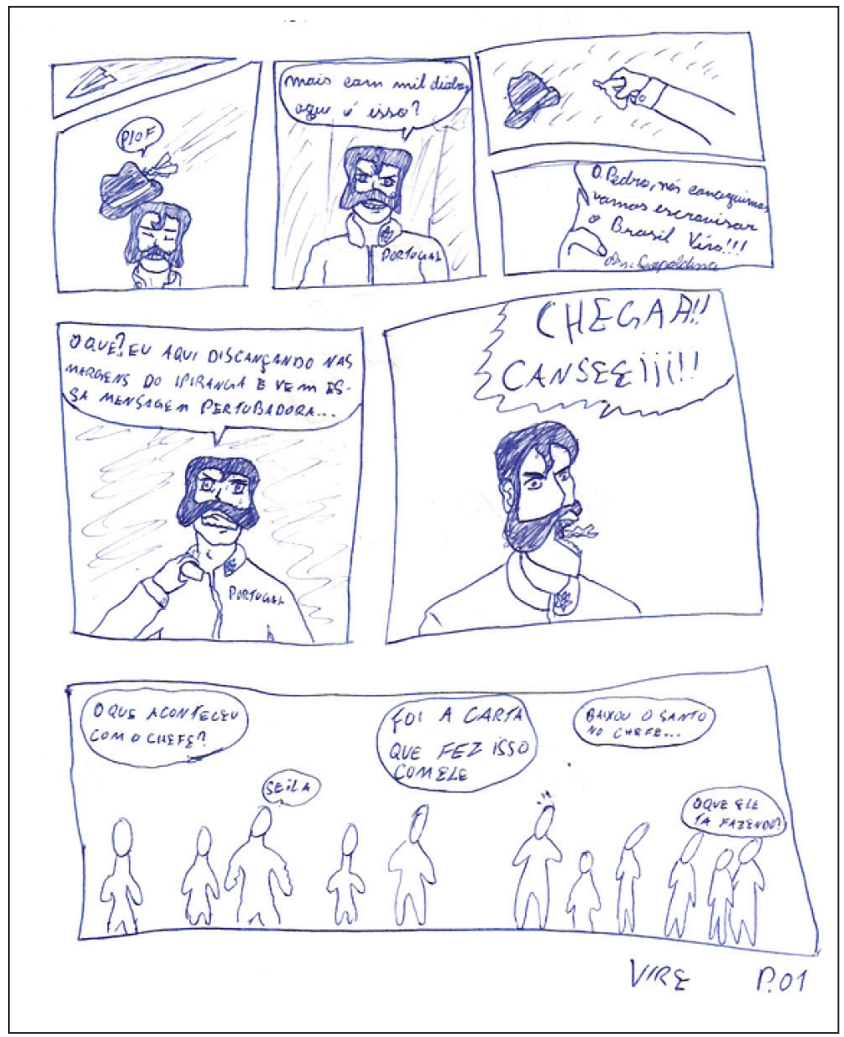

Figura 5 - Caio Márcio, 16 anos, Vitória da Conquista, BA (p.2)

Essa narrativa em quadrinhos de Caio Márcio é surpreendente, pois ela inicia com a distorção de uma atitude afirmativa típica de uma consciência histórica tradicional, ao apresentar o personagem D. Pedro indignado com a mensagem que chegou na forma de um aviãozinho de papel. Após um quadrinho que representa seus soldados em suspense com o que teria acontecido a seu chefe, D. Pedro aparece, no último quadro, transformado em um guerreiro medieval cristão (o personagem usa o símbolo dos cavaleiros templários) montado sobre um cavalo branco alado (animal comum nos mangás japoneses).

Essa transformação de uma pessoa ou ser normal em seres super-humanos ou místicos é uma referência clara às estratégias estéticas dos mangás. Classifiquei essas imagens como expressões de uma consciência histórica crítica porque elas desestruturam, negando pela raiz, a iconografia canônica sobre 
a Independência. Esse jovem criou uma imagem alternativa da Independência, mesmo que sua intenção pudesse ser a de adesão às narrativas tradicionais.

Mas o ato criativo desse jovem, ao mobilizar duas tradições narrativas das histórias em quadrinhos - a das histórias de super-heróis, representadas pelos diálogos dos soldados, e a dos mangás pela já referida transformação mágica dos personagens - para expressar uma narrativa humorística, determina o caráter de negação das tradições em prol de uma tradição seletiva, ligada à cultura juvenil e aos quadrinhos (Williams, 2003; Snyders, 1988). Há mais um indício da forma de subjetivação desse jovem em relação à arte dos quadrinhos: a assinatura do seu nome artístico, Boy Doido, como autor dos quadrinhos. Novamente, como os outros estudantes categorizados, Caio Márcio apresenta uma relação de intersubjetividade com relação ao conhecimento histórico mediado pela dimensão estética dos quadrinhos alterando, assim, os significados e valores das narrativas tradicionais.

É notável, nos dois jovens investigados nesta categoria, que ambos, nas outras perguntas do estudo final, expressaram argumentos voltados para uma atitude intersubjetiva claramente voltada para uma consciência histórica tradicional. Quando desenham as histórias em quadrinhos, elas são transmutadas em histórias que negam a tradição, ao menos na forma, e em parte do conteúdo. Eles realizam essa dimensão crítica da consciência histórica porque mobilizam imagens alternativas vindas de tradições populares ou da cultura juvenil, que quebram o efeito de realidade mobilizado por imagens e estilos canônicos (Saliba, 1999; Lukács, 2010), inviabilizando a "fatalidade fetichista" presente nesses cânones.

A intersubjetividade expressa por esses sujeitos é tudo, menos fatalista, pois a humanidade, resgatada sob a máscara do cômico, expressa sua vitalidade num ato criativo (Lukács, 2003), que dialoga com as tradições antes esquecidas do passado e que apresentam perspectivas de um salto para o futuro (Bakhtin, 1997; 2000).

Essas expectativas de liberdade e igualdade entre os homens são o que orienta as duas histórias em quadrinhos a serem analisadas a seguir.

Luigia é filha de uma dona de casa e de um lavrador. Sempre morou em São João dos Patos, no Maranhão, e sempre estudou na escola pública. Entre outras atividades de lazer, ela aprecia histórias em quadrinhos e tocar violão. Defende que o conhecimento histórico faz o "nosso passado" propiciar a 
compreensão do "nosso presente". Revelou conhecer uma história em quadrinhos que conta a história da humanidade: Asterix e Cleópatra, e narra como ocorreu, para ela, a criação do Egito, do poder da República romana e da disputa entre Roma, dominada por César, e o Egito governado por Cleópatra. Ela afirma que as pirâmides são uma prova de que o Egito existiu e da plausibilidade da narrativa em quadrinhos.

Considera possível aprender historicamente com as histórias em quadrinhos, pois estas transformam a História em "comédia, romance, ciência" e muitas outras coisas que foram realizadas no passado. Segundo ela, os quadrinhos correspondem às narrativas que são ensinadas nas aulas de História.

Ela foi uma das poucas estudantes que apresentou um anacronismo ao confundir D. Pedro com Pedro Álvares Cabral. Defendeu que ele era um salvador da nação. Considerou como uma situação do passado relevante o Hino da Independência e, também que essa canção é uma prova da realidade da Independência do Brasil.

Suas argumentações estão vinculadas à importância da memória histórica como fator de identidade. Apesar da dubiedade de algumas respostas reveladas pelos anacronismos, ela aponta para uma consciência histórica tradicional.

Eis como representa em quadrinhos as suas ideias:

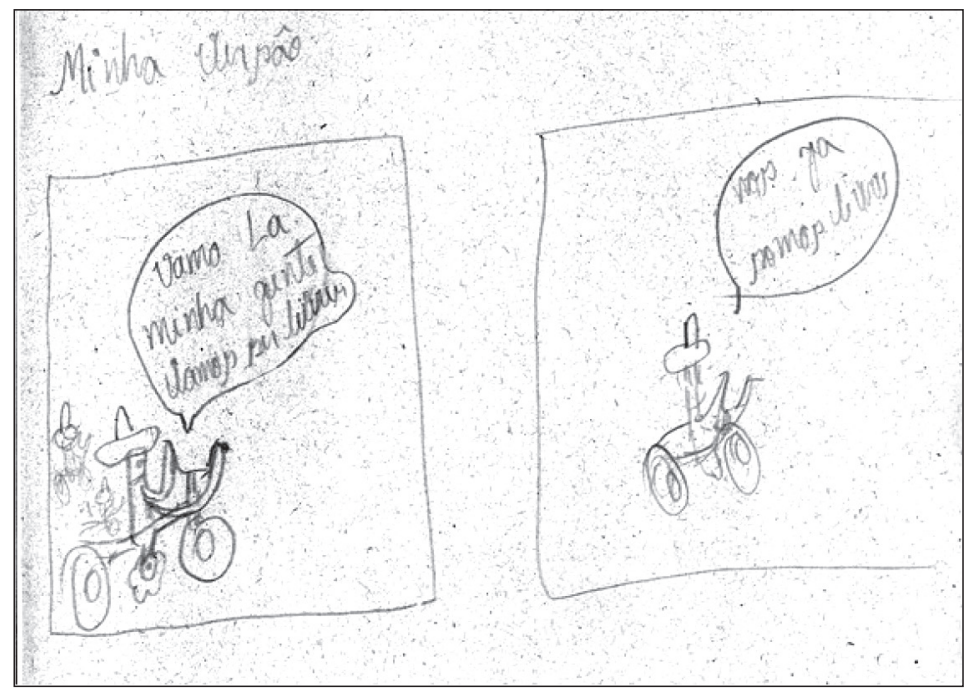

Figura 6 - Luigia, 18 anos, São João dos Patos, MA 
À primeira vista, a história em quadrinhos composta por Luigia poderia representar indícios de uma atitude vinculada a uma consciência histórica exemplar, pois foca o tempo de sua narrativa no presente por causa das imagens de uma jovem com bicicleta. No entanto, o conteúdo dos balões do personagem expressa um diálogo transformador em relação à narrativa tradicional implícita sobre a Independência do Brasil (Wertsch; Rozin, 2004; Wertsch, 2006). Esse diálogo transformador está representado pela consciência do personagem: os jovens hoje são livres. A força dessa conquista da dignidade humana, que se expressa na liberdade dos jovens no interior do Brasil, representa uma mudança histórica em relação ao Brasil representado nas duas versões em quadrinhos. A intersubjetividade dessa jovem em relação ao conhecimento histórico está pautada no valor da liberdade.

Contudo, o que para mim determina o caráter ontogenético da consciência história expressa nessa narrativa gráfica é a ausência da imagem canônica de D. Pedro proclamando a Independência. A negação dessa imagem canônica, transformada em algo lúdico como a imagem alternativa de um jovem correndo numa bicicleta, com a consciência da liberdade conquistada após muitos anos de escravidão e sujeição, pode ser uma pista em relação às estratégias estéticas dos jovens como uma forma da liberação das dimensões cognitivas, políticas e éticas da cultura histórica. Enquanto esse conceito ainda está germinando nos quadrinhos de Luigia, a ideia da transformação de uma imagem canônica em uma imagem alternativa, estruturada pela ausência da primeira, é o que parece orientar a história em quadrinhos da próxima jovem estudante a ser investigada.

Filha de uma gerente de loja e digitadora e de um contabilista, Marjane sempre estudou na escola pública e sempre viveu em Curitiba, Paraná. Entre outras atividades de lazer ela gosta de ler histórias em quadrinhos. Defende que a História se resume na busca pelo passado por ele mesmo e acredita que é possível aprender história com os quadrinhos, porque é divertido e permite escapar da rotina das constantes leituras exigidas pela cultura escolar. Afirma que as histórias em quadrinhos podem contar a verdade, dependendo da disposição do autor.

Contudo, Marjane argumenta que a história é multiperspectivada e nunca poderia ser definitivamente verdadeira porque cada testemunha contaria a história sob seu próprio ponto de vista e o historiador teria de escolher o mais 
provável. Defende, por fim, que somente as testemunhas de época e os participantes da situação do passado têm condições de narrar a verdade, mas ela acha possível que um autor contemporâneo possa fazer bons quadrinhos de História.

Marjane aparentemente oscila entre uma consciência histórica tradicional, pautada em uma verdade dogmática sobre o passado, e uma atitude multiperspectivada e relativista. A perspectividade por ela defendida está no nível das evidências inferidas a partir de fontes primárias (Borries, 2001, p.102).

Assim ela expressa em quadrinhos suas ideias:

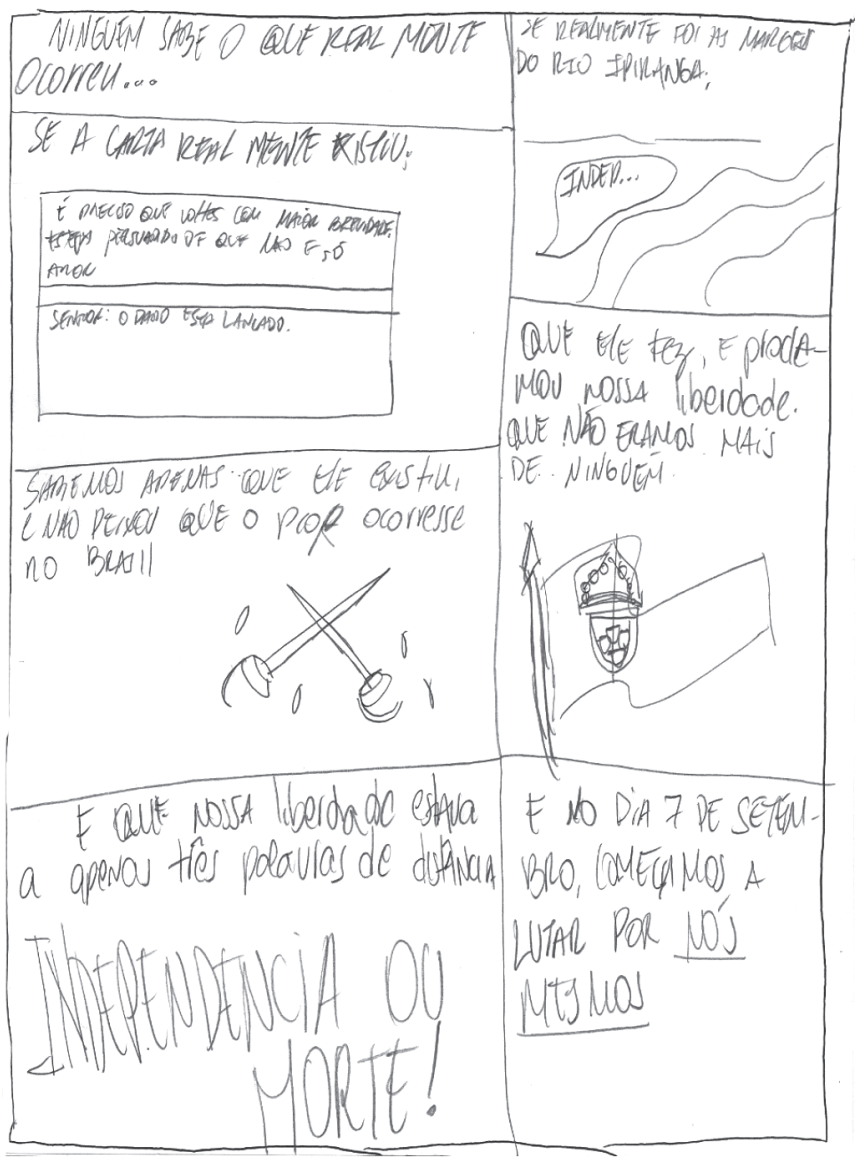

Figura 7 - Marjane, 16 anos, Curitiba, PR 
Marjane compôs uma história em quadrinhos que apresenta um diálogo entre a narrativa tradicional sobre a Independência do Brasil e uma nova narrativa aberta para o futuro. É isso o que expressa uma atitude de transformação em relação à tradição e em prol de uma consciência histórica ontogenética. A narrativa tradicional, fundadora da identidade nacional, é incorporada sob uma nova interpretação, vinculada à liberdade e dignidade humanas como um princípio universal que, antes, estava vedada aos brasileiros. A narrativa dessa jovem põe em dúvida a precisão dos marcos espaciais e dos acontecimentos que levaram à Independência.

Nas três primeiras tarjas expressa essas dúvidas quanto à realidade das experiências ligadas à localização do evento no riacho Ipiranga, e da existência da carta recebida por D. Pedro nesse local. O caráter evanescente das imagens alternativas é flagrante, pois em um balão do segundo quadrinho a palavra Independência aparece só parcialmente como que desaparecendo da imagem. A narrativa afirma, na quarta tarja, que D. Pedro realmente existiu e evitou que uma guerra civil acontecesse. A ideia de guerra está representada pela expressão "o pior acontecesse" e pela imagem alternativa de duas espadas se digladiando. Aparentemente, a narrativa, a partir desse ponto, toma um rumo de afirmação da imagem da bandeira imperial e da clássica frase "Independência ou morte"; mas o valor que mobiliza esses quadros, à primeira vista tradicionais, é a liberdade, que no início está vinculada às ações e intenções de D. Pedro. Mas no último quadrinho, mesmo com a referência temporal da data de 7 de setembro, a liberdade sai da referência ao personagem histórico e passa a ser compartilhada por todos os brasileiros com a frase "começamos a lutar por nós mesmos".

O diálogo entre imagens canônicas e imagens alternativas parece revelar que D. Pedro era uma espécie de estopim para algo que esse personagem nem imaginava: a busca da liberdade do povo brasileiro, no qual Marjane se define como integrante, pois sempre usa a primeira pessoa do plural e o pronome possessivo "nosso". É perceptível que, para evitar o poder dos ícones canônicos, essa jovem não representou o personagem $\mathrm{D}$. Pedro, mas somente a sua fala, como se fosse uma senha para uma mudança histórica estrutural que sequer tinha imaginado: o processo histórico que culminou, no futuro do passado, com a liberdade de todo o povo brasileiro que a toma em suas mãos. 
Possivelmente, esse é o significado da invisibilidade desse personagem nos quadrinhos.

As palavras têm um importante papel como imagens alternativas nesta narrativa gráfica (McCloud, 2005), pois é no diálogo entre imagem e palavra que o significado histórico e o valor para a orientação de sentido do tempo na vida prática se expressam.

Compreendo que essa mudança cognitiva nos tipos de consciência histórica entre atitude tradicional fornecida pelas respostas às outras questões do estudo final e a disposição de transformação histórica das histórias em quadrinhos produzida por essa jovem se deve ao modo como ela mobilizou a estetização desses artefatos da cultura histórica. Ao realizar o ato criativo de produzir uma história em quadrinhos, eles propiciaram um salto (Lukács, 2003) na qualificação de sua consciência histórica, passando de uma concepção dogmática da verdade para uma percepção da plausibilidade das narrativas históricas que integram a sua identidade, por meio do reconhecimento da identidade do outro que viveu no passado e que vive no presente.

\section{CONSIDERAÇÕES FINAIS}

Constatei que a mudança de um tipo de consciência histórica para outra mais sofisticada não acontece somente de forma progressiva, mas também mediante saltos e recuos. Isso porque na consciência de um sujeito existem as quatro formas de disposição da consciência histórica - a afirmação, a exemplaridade, a negação e a transformação - e elas são mobilizadas de acordo com a forma de estruturação das relações intersubjetivas dos jovens aqui investigados com o conhecimento histórico.

É preciso ter em mente também que a consciência histórica de um indivíduo não se esgota nele mesmo, porque ela é intersubjetiva e interpessoal (Bakhtin, 1997) e, por isso, está em constante diálogo com a consciência histórica do outro. Entendo, portanto, que o salto acontece não somente por causa de uma relação lógica entre esses quatro tipos de consciência histórica, mas porque cada um deles se relaciona de uma determinada maneira com a forma de internalizar a mudança do tempo histórico presente no processo histórico real da vida humana prática (Rüsen, 2007; 2010). 
A onipresença da imagem canônica do grito da Independência, representada pela pintura de Pedro Américo, que é reproduzida em todos os livros didáticos de História brasileiros, inclusive nas versões em quadrinhos confrontadas nesta investigação, produz, por causa disso, um deficit de sentido que impõe aos estudantes ficarem presos ao presente eterno de um momento do passado. Marjane compreendeu que a supressão da imagem canônica é uma das possibilidades, talvez a única, de expressar o poder de transformação do tempo histórico, de um modo que dê sentido a suas vidas, supere a visão presentista e possibilite tomar consciência da intersubjetividade com conhecimento histórico.

Segundo Rüsen (2001, p.173), quando uma determinada experiência do passado não permite a apreensão do significado histórico da constituição narrativa de sentido, é necessário lançar mão de uma "dialética negativa da constituição de sentido" para que a dimensão da historicidade humana seja explicitada ao narrar. Defendo que essa jovem mobilizou a dimensão estética da cultura histórica, relacionada aos quadrinhos, para libertar o sentido cognitivo e ético do significado de uma experiência do passado, por meio de uma negação dialética. As narrativas tradicionais e as imagens canônicas sobre a Independência recalcaram há tempos o significado histórico não realizado nessa experiência do passado e ainda por se cumprir no presente, que dá sentido às expectativas de futuro: o de que todos os homens e mulheres são dignos de serem reconhecidos como livres e iguais.

\section{REFERÊNCIAS}

BAKHTIN, Mikhail M. Problemas da poética de Dostoiévski. Rio de Janeiro: Forense Universitária, 1997.

Observações sobre e epistemologia das ciências humanas. In: . Estética da criação verbal. 3.ed. São Paulo: Martins Fontes, 2000. p.399-414.

BORRIES, Bodo von. "Multiperspectivity": utopian pretention or feasible fundament of historical learning in Europe? In: LEEUW-ROORD, Joke van der (Ed.) History for today and tomorrow: what does Europe mean for School History? Hamburg: Körber Stiftung, 2001.

EISNER, Will. Quadrinhos e arte sequencial. São Paulo: Martins Fontes, 1999.

FRONZA, Marcelo. A intersubjetividade e a verdade na aprendizagem histórica de jovens estudantes a partir das histórias em quadrinhos. Tese (Doutorado em Educa- 
ção) - Programa de Pós-Graduação em Educação, Universidade Federal do Paraná. Curitiba, 2012.

LESSARD-HÉBERT, Michelle; GOYETTE, Gabriel; BOUTIN, Gérald. Investigação qualitativa: fundamentos e práticas. Lisboa: Instituto Piaget, 2005.

LUKÁCS, György. História e consciência de classe: estudos sobre a dialética marxista. São Paulo: Martins Fontes, 2003. . Marxismo e teoria da literatura. 2.ed. São Paulo: Expressão Popular, 2010.

MCCLOUD, Scott. Desvendando os quadrinhos. São Paulo: Makron Books, 2005. . Reinventando os quadrinhos. São Paulo: Makron Books, 2006.

SALIBA, Elias Tomé. As imagens canônicas e o Ensino de História. In: SCHMIDT, Maria A.; CAINELLI, Marlene R. (Org.) III Encontro Perspectivas do Ensino de História. Curitiba: Aos Quatro Ventos, 1999. p.434-452.

RÜSEN, Jörn. A razão histórica. Teoria da história: os fundamentos da ciência histórica. Brasília: Ed. UnB, 2001.

. História viva. Teoria da História III: formas e funções do conhecimento histórico. Brasília: Ed. UnB, 2007.

. Narratividade e objetividade nas ciências históricas. In: SCHMIDT, Maria A.; BARCA, Isabel; MARTINS, Estevão de R. (Org.) Jörn Rüsen e o ensino de História. Curitiba: Ed. UFPR, 2010. p.129-150.

Aprendizagem histórica: esboço de uma teoria. In: RÜSEN, Jörn. Aprendizagem histórica: fundamentos e paradigmas. Curitiba: W. A. Editores, 2012. p.69112.

SCHMIDT, M. A. Cognição histórica situada: que aprendizagem histórica é essa? In: SCHMIDT, Maria A.; BARCA, Isabel. Aprender História: perspectivas da Educação Histórica. Ijuí: Ed. Unijuí, 2009. p.21-51.

SNYDERS, Georges. Alegria na escola. São Paulo: Manole, 1988.

TIRINHA com xingamento derruba o secretário de Educação do estado. A Tarde, Salvador, 4 ago. 2009. Disponível em: http://www.atarde.com.br/noticia. jsf?id=1201189; Acesso em: 10 ago. 2015.

WERTSCH, James V.; ROZIN, Mark. La Revolución Rusa: versions oficiales y no oficiales. In: CARRETERO, Mario; VOSS, James F (Org.) Aprender y pensar la historia. Buenos Aires: Amorrortu, 2004. p.121-150.

WERTSCH, James V. Specific narratives and schematic narratives templates. In: SEIXAS, Peter (Ed.) Theorizing historical consciousness. Toronto: University of Toronto Press, 2006. p.49-62.

WILLIAMS, Raymond. La larga revolución. Buenos Aires: Nueva Visión, 2003. 


\section{NOTAS}

${ }^{1}$ O historiador inglês Peter Lee (2006) estabelece alguns princípios da cognição histórica: os conceitos substantivos referem-se aos conteúdos específicos da História, tais como Egito Antigo, Império Romano, Renascimento, Revolução Industrial etc.; e os conceitos de segunda ordem são os que estão ligados às ideias históricas estruturais do pensamento histórico, qualquer que seja o conteúdo, tais como as categorias temporais - permanências, rupturas, periodizações etc. - e também aquelas relacionadas às formas de compreensão histórica, como os conceitos de explicação histórica, evidência, inferência, empatia, significância, imaginação, objetividade, verdade e narrativa históricas.

${ }^{2}$ Os nomes dos estudantes investigados são fictícios. Foram baseados em personagens de histórias em quadrinhos ou personagens históricos já quadrinizados.

${ }^{3}$ Essa é uma possível referência ao caso de uma polêmica tirinha em quadrinhos que foi alterada e estava presente num material paradidático da Bahia, que levou à demissão do secretário da Educação do estado. Isso mostra a força do uso público desses artefatos na cultura escolar e os problemas éticos que a sociedade enfrenta com a introdução da arte em quadrinhos nas escolas. Informação disponível em: http://www.atarde.com.br/politica/noticia.jsf?id=1201135; Acesso em: 10 ago. 2015.

Artigo recebido em 15 de agosto de 2015. Aprovado em 15 de outubro de 2015. 